\title{
La diacronía en el Diccionario panhispánico de dudas: el género gramatical*
}

\author{
CRISTINA BUENAFUENTES DE LA MATA Y CARLOS SÁNCHEZ LANCIS
}

Universidad Autónoma de Barcelona

\section{INTRODUCCIÓN}

En la evolución del latín al español, la pérdida casual y la desgramaticalización del género neutro provocaron una profunda reestructuración del sistema del género gramatical (Menéndez Pidal 1940, Alvar y Pottier 1983, Lloyd 1987/1993, Urrutia y Álvarez 1988, Penny 1991/1993, Rodríguez Díez 2005, entre otros), que conllevó una serie de cambios en su determinación en muchas voces. Aunque existió una tendencia más o menos generalizada que asignaba el género en función de la terminación ( $-a$ para el femenino y -o para el masculino), lo cierto es que existían muchas palabras cuya parte final no se correspondía con ninguno de estos dos morfemas y en las que, por lo tanto, se producía el mayor número de vacilaciones.

Aunque podría pensarse que esta indeterminación sólo pertenece a las primeras etapas históricas del español, los problemas en la asignación de género en la actualidad también son de gran importancia, por lo que en estos casos es la norma la encargada de solventar las dudas del hablante al respecto. Así, aunque a partir del Diccionario de la lengua española (2001) de la Real Academia Española se pueden solucionar algunos de estos problemas (véase Buenafuentes y Sánchez Lancis 2006), gracias a la publicación en 2005 del Diccionario panhispánico de dudas $[D P D]$, también de la RAE, por fin el usuario dispone de una herramienta normativa imprescindible para resolver tanto las dudas relativas al género en concreto, como otras cuestiones derivadas del uso (véase Velando 2006, Azofra 2007, Buenafuentes y Sánchez Lancis 2008).

Como es bien sabido, cualquier diccionario de dudas debe basar sus decisiones en el uso actual de la lengua y el $D P D$ no es ajeno a esta cuestión. De hecho, así lo señala en su prólogo:

El Diccionario panhispánico de dudas, teniendo muy presente la realidad del cambio lingüístico [...], basa sus juicios y valoraciones en la norma efectivamente vigente en el español actual, considerado este como la lengua que emplean las generaciones vivas de habla española. En ningún caso se ha conformado con repetir juicios heredados de la tradición normativa, sino que [...] ha podido analizar la pervivencia y extensión real de los usos comentados y ofrecer, por tanto, soluciones y recomendaciones fundadas en la realidad lingüística presente ( $D P D$ : XIV).

* La presente investigación, versión muy ampliada y revisada de un trabajo presentado en el XXV Congrès International de Linguistique et de Philologie Romanes, ha sido parcialmente financiada con una ayuda del MEC y FEDER ( $\mathrm{n}^{\mathrm{o}}$ de ref. HUM2005-08149-C02-01/FILO y HUM2006-13295-C02-02) y de la CIRIT del Comissionat per Universitats $i$ Recerca de la Generalitat de Catalunya ( $\mathrm{n}^{\circ}$ de ref. 2005SGR 00568). 
Sin embargo, pese a que en el prólogo se afirma que esta obra no repite «los juicios heredados de la tradición normativa», lo cierto es que el criterio etimológico (tan habitual en el establecimiento de las normas ortográficas) está también presente en un diccionario tan actual como el $D P D$. Esto es una muestra más de lo difícil que resulta separar norma, uso y diacronía.

Por tanto, el objetivo de la presente investigación es analizar las informaciones de tipo histórico que aparecen en este diccionario y que hacen referencia al género de las voces que en él se recogen, para poder demostrar que la diacronía juega un papel importante en el establecimiento de la norma gramatical. Para ello, se van a tratar los tres criterios que, en nuestra opinión, vertebran el género en el $D P D$. En primer lugar, el criterio etimológico, que emplea la diacronía para ratificar o rechazar el género de una palabra. Por otro lado, se utiliza un segundo criterio, que se basa en la historia de la lengua y que remite a períodos anteriores del español (español medieval, español clásico, etc.) como contraste o apoyo a la solución normativa propuesta. Y, finalmente, el criterio del uso actual, que en teoría debería ser el único y principal hilo conductor del diccionario, pero que, como se demostrará, comparte protagonismo con lo histórico en la asignación del género de las palabras. En definitiva, como se podrá comprobar a partir de este estudio, la determinación de este rasgo morfológico es el resultado de un largo y complejo camino, que sólo la adopción de una perspectiva histórica puede ayudar a descubrir y comprender.

\section{NORMA Y DIACRONÍA}

\subsection{EL CRITERIO ETIMOLÓGICO COMO NORMA}

Como se ha señalado en la introducción, las palabras que aparecen recogidas en el $D P D$ con datos relativos a su género presentan, en muchas ocasiones, informaciones de tipo histórico. Estas referencias diacrónicas se exponen normalmente de manera explícita mediante el uso de expresiones como «en sus orígenes», «desde el punto de vista etimológico» o «como en latín». Sin embargo, el mecanismo más empleado por el diccionario en este sentido es la indicación directa del género del étimo del que procede la voz. Este es el caso de vocablos como alfoz, boa, herpes o testuz, tal y como puede observarse a continuación:

alfoz. [...]. Aunque en sus orígenes se empleó en ambos géneros, en el español moderno es exclusivamente masculino (DPD: s. v. alfoz).

boa. Cuando significa 'serpiente americana de gran tamaño', aunque alguna vez se ha usado en masculino, es de género femenino, como en latín (DPD: s. v. boa).

herpes. [...]. Procede del latín herpes y hoy se emplea exclusivamente con el género masculino etimológico (DPD: s. v. herpes).

testuz. [...]. Este sustantivo, originariamente masculino, pasó a usarse también en femenino por influjo de cabeza, y hoy se admiten ambos (DPD: s. v. testuz).

Como se puede comprobar, la mayor parte de estas indicaciones son breves y ayudan al usuario a comprender la evolución que ha experimentado una palabra en cuanto a su género. Sin embargo, existen casos, como mar o regaliz, en los que el DPD ofrece una completísima historia de la palabra, hecho que reafirma claramente la fuerza explicativa del criterio etimológico en el establecimiento de la norma: 
mar. [...]. Este sustantivo, neutro en latín, se ha usado en español en ambos géneros. En el español general actual es masculino [...]; pero entre las gentes de mar (marineros, pescadores, etc.) es frecuente su empleo en femenino, que también abunda en poesía (DPD: s. v. mar).

regaliz. [...]. El étimo latino es femenino y, de hecho, en el español primitivo se usó en un principio la forma femenina regaliza, que posteriormente perdió la - a por influjo de la terminación en $-z$ del sinónimo de origen árabe orozuz. La forma regaliz adoptó pronto el género masculino con el que se usa hoy en la lengua general culta [...]. Debe evitarse su uso en femenino ( ${ }^{\circledast}$ la regaliz), achacable hoy, por lo general, al influjo de otras lenguas, como el catalán, donde el equivalente de esta voz mantiene el género etimológico (DPD: s. v. regaliz).

Una vez comprobada la presencia de la diacronía en el $D P D$, conviene analizar los diferentes usos con los que se emplea en el diccionario. Así, la etimología se utiliza muy frecuentemente para reafirmar o rechazar un determinado género. Mediante este criterio justificativo, el $D P D$ señala que voces como clímax, dracma, enfiteusis, índole o sazón son masculinas o femeninas «como su étimo latino»:

clímax. Con el sentido de 'punto más alto o culminación de un proceso', es masculino [...]. Pero en el lenguaje científico, con el sentido de 'situación óptima de un ecosistema dadas las condiciones del medio en el que se desarrolla’, se usa con el género femenino etimológico (DPD: s. v. clímax).

dracma. [...]. Se recomienda el género femenino, que es el etimológico (DPD: s. v. dracma).

índole. [...]. Es voz femenina, como su étimo latino (DPD: s. v. índole).

Esta información etimológica es muy apropiada sobre todo en aquellos casos en los que no existe una marca morfológica de género (- $a$ para el femenino, - $o$ para el masculino), como en el vocablo haz:

haz. Cuando significa 'conjunto homogéneo de cosas alargadas atadas por el centro' y 'conjunto de rayos luminosos que emanan de un mismo punto', procede del latín fascis ('fajo, manojo') y es, como su étimo latino, de género masculino [...]. Cuando significa 'cara de una cosa habitualmente más visible o destinada a ser vista', procede del latín facies ('cara') y es, como su étimo, de género femenino, aunque al comenzar por /a/ tónica, le corresponde en singular la forma el del artículo [...]. Cuando significa 'tropa formada', procede del latín acies ('fila de soldados'), que era femenino, género con el que debe usarse también en español (DPD: s. v. haz).

Esta justificación se extiende también a aquellas palabras que no proceden del latín, pero en las que el género de la lengua de origen es el que marca el de la voz en español, como sucede en los ejemplos siguientes:

boa. [...]. Cuando significa 'prenda en forma de serpiente, para adorno o abrigo del cuello', aunque hace años se usaba siempre con el género masculino que tiene esta voz en francés, hoy es más frecuente el femenino (DPD: s. v. boa).

gripe. [...]. Es voz femenina, como en francés, lengua de donde la hemos tomado (DPD: s. v. gripe).

Esto implica que, desde la forma etimológica a la del español actual, el vocablo haya experimentado una serie de cambios de género con respecto a su étimo (pasando, en ocasiones, 
por etapas previas de vacilación). Es en estos casos en los que el diccionario realiza explicaciones diacrónicas más extensas y detalladas, pues debe dar cuenta de qué ha ocurrido para que el género de la palabra haya cambiado en su evolución al español.

En otras ocasiones, el género etimológico aparece como contraste a la solución que se usa en la actualidad. Esto ocurre con palabras como ánade, apocalipsis, chinche, crin u hojaldre, en las que el $D P D$ señala explícitamente que pese a que su género etimológico es uno, en español actual se emplea mayoritariamente otro:

ánade. [...]. Aunque el género etimológico es el femenino, hoy se emplea mayoritariamente en masculino (el ánade blanco, los ánades blancos) (DPD: s. v. ánade).

apocalipsis. [...]. Aunque alguna vez se emplea con el género femenino etimológico, es hoy mayoritario y preferible su uso en masculino (DPD: s. v. apocalipsis).

chinche. [...]. Aunque el étimo latino es masculino, cambió de género ya en latín vulgar y en español ha sido siempre femenino en el uso culto mayoritario de todo el ámbito hispánico ( $D P D$ : s. v. chinche).

crin. [...]. Aunque en latín clásico era voz masculina, en el español general culto, desde la época medieval, es mayoritario su uso en femenino: la crin, las crines. No obstante, en algunos países de América y en el habla de algunas regiones españolas se usa ocasionalmente con el género masculino etimológico (DPD: s. v. crin).

hojaldre. [...]. Aunque en épocas pasadas se usó en ambos géneros, en el español actual es siempre masculino (DPD: s. v. hojaldre).

A pesar de que podría pensarse que estas referencias etimológicas son superfluas, en nuestra opinión hacen más comprensibles las vacilaciones en el género y la solución adoptada desde el punto de vista normativo. Por ello, consideramos que debería generalizarse este empleo a otras voces que no presentan este tipo de información y en las que sólo se señala su género en el español actual. Este es el caso de vocablos como apéndice o vinagre, en los que el diccionario sólo señala que «este sustantivo es masculino en el español general culto», sin aportar ningún dato más que ayude a entender por qué las dos voces son masculinas si, además, antiguamente fueron empleadas en ambos géneros y en español actual no son extraños los usos anómalos y no normativos de las dos palabras en femenino (*la apéndice o *la vinagre), como puede comprobarse en el Corpus diacrónico del español (CORDE) y en el Corpus de referencia del español actual (CREA). En nuestra opinión, las informaciones diacrónicas deberían ampliarse a todos los casos en los que puede haber dudas en cuanto al género.

Asimismo, la información diacrónica es de gran utilidad sobre todo en aquellas palabras que proceden de sustantivos neutros latinos, ya que al desgramaticalizarse el género neutro sufrieron una reestructuración (en algunos casos bastante aleatoria) hacia el femenino o el masculino; y también en aquellos vocablos que no presentaban una clara marca morfológica de género, por lo que conocerlo resulta más complicado. Esto ocurre, por ejemplo, con los sustantivos en -or o con las palabras terminadas en -umbre:

calor. [...]. Es voz masculina en la lengua general culta [...]. Su uso en femenino, normal en el español medieval y clásico, se considera hoy vulgar y debe evitarse. El femenino puede aparecer también en textos literarios, con finalidad arcaizante (DPD: s. v. calor).

vislumbre. [...]. Aunque en épocas pasadas se usó frecuentemente en femenino, en el español actual predomina el masculino (DPD: s. v. vislumbre). 
Además, la información diacrónica se hace más necesaria cuando la solución en el género de algunas voces es doble, es decir, poseen un género ambiguo, como sucede con el vocablo mar, visto antes, o acné, entre otros:

acné. [...]. En el español actual se emplea casi exclusivamente en masculino [...]. Es hoy raro, pero admisible, su uso con el género femenino etimológico (DPD: s. v. acné).

Por otro lado, las referencias históricas son escasas en otros casos que también pueden plantear problemas de género al usuario. Esto ocurre, por ejemplo, en las excepciones a la tendencia de reasignación del género de las palabras neutras señalada antes. Se trata de vocablos masculinos que terminan en - $a$ en los que, por tanto, no existe la correspondencia entre la terminación y el género. Durante su evolución, estas voces presentaron vacilación, pero finalmente acabaron por adquirir el género masculino. En este sentido, debería ampliarse la información diacrónica (escasa o inexistente) que se ofrece en palabras de procedencia griega como anatema, aneurisma, aroma o cisma.

También se han hallado casos en los que, pese a que el género etimológico y el género del español actual no coinciden, el $D P D$ señala que ambos son válidos (aunque en ocasiones se indique la preferencia por el masculino o el femenino). En estas voces, como, por ejemplo, crepe o sílice, la diacronía también resulta clarificadora, ya que el usuario puede llegar a comprender por qué determinadas palabras se pueden usar en ambos géneros:

crepe. [...]. Es válido su uso en ambos géneros, aunque se recomienda mantener el género femenino etimológico (DPD: s. v. crepe).

sílice. [...]. Ya en latín vacilaba su género. En español, aunque se documenta ocasionalmente en masculino, ha sido siempre femenino en el uso culto mayoritario (DPD: s. v. sílice).

Aparte de poder conocer cuál ha sido la evolución experimentada por la palabra en este aspecto, el $D P D$ señala también a veces la causa por la cual el género del vocablo ha cambiado con respecto a su étimo. En estas ocasiones, lo más frecuente es que se indique otra palabra afín semánticamente que influye en el cambio de género de otra voz. En algunos casos, el resultado de esta influencia se considera válido (como en aguatinta, magneto, maratón, prez o pitón); en otros, se censura normativamente (como en avestruz e hidromiel):

aguatinta. [...]. Aunque tradicionalmente se ha considerado de género femenino, hoy, por influjo de aguafuerte, es frecuente su empleo en masculino. Se admite su uso en ambos géneros (DPD: $s$. v. aguatinta).

avestruz. [...]. Es voz masculina [...]. Por influjo del género de la palabra ave, se comete a menudo el error de usarla en femenino: ${ }^{\otimes}$ la avestruz (DPD: s. v. avestruz).

hidromiel. [...]. Esta voz, neutra en latín, es masculina en español [...]; a veces, por influjo de miel, se usa indebidamente en femenino: ${ }^{\otimes}$ la hidromiel (DPD: s. v. hidromiel).

magneto. [...]. Surge por abreviación de la expresión máquina magnetoeléctrica, lo que explica su inicial uso en femenino, aún vigente [...]. Pero hoy es cada vez más frecuente su empleo en masculino, influido por la terminación en -o de este sustantivo (DPD: s. v. magneto).

maratón. [...]. Esta voz comenzó a circular en el primer tercio del siglo xx con género masculino; posteriormente, por influjo del género de prueba o carrera, se ha ido extendiendo su uso en femenino, también válido (DPD: s. v. maratón). 
prez. [...]. Era en origen un sustantivo masculino, como precio, con el que comparte étimo latino. Posteriormente, quizá por influjo de sinónimos como honra o fama, o del sustantivo preces, comenzó a emplearse también en femenino y hoy se considera válido su uso en ambos géneros (DPD: s. v. prez). pitón. Este sustantivo es masculino en todas sus acepciones; también cuando designa cierta serpiente no venenosa de gran tamaño [...]. Pero hoy es más frecuente su uso en femenino, por influjo del género del sustantivo serpiente, con el que aparece a menudo en aposición (serpiente pitón) (DPD: s. v. pitón).

A veces, es la influencia de otra lengua la que favorece el hecho de que el género de una determinada palabra cambie. Esto puede llevar a dos soluciones distintas. La primera de ellas consiste en que el resultado de ese influjo sea rechazado por el $D P D$ por considerarlo incorrecto. Esto ocurre en vocablos como claror o psicoanálisis, tal y como puede observarse a continuación:

claror. [...]. Se ha usado en ambos géneros. En el español medieval era normalmente femenino, pero hoy es mayoritario su empleo con el género masculino etimológico [...]. En algunos hablantes, el uso en femenino ( ${ }^{\otimes}$ la claror) puede deberse al influjo del catalán (DPD: s. v. claror).

psicoanálisis. [...]. Debe usarse siempre en masculino, como mayoritariamente se hace, por ser este el único género válido en el español actual para el sustantivo análisis [...]. Debe evitarse su uso en femenino $\left({ }^{\otimes}\right.$ la psicoanálisis), achacable hoy al influjo de otras lenguas como el italiano, el francés o el catalán, en las que análisis y sus compuestos son de género femenino (DPD: s. v. psicoanálisis).

La otra solución, más minoritaria, es que el cambio de género venga dado por la influencia de otra lengua, pero el resultado se adapte a la norma del español. Esto se puede observar en palabras como cantatriz o samba:

cantante. [...]. El femenino cantatriz (que etimológicamente corresponde al masculino cantador) es desusado en español y se desaconseja su empleo. Su uso ocasional hoy, normalmente referido a la cantante de ópera o de canto clásico, se debe más al influjo de otras lenguas, como el italiano o el francés (DPD: s. v. cantante).

samba. [...]. Es voz femenina en la mayor parte del ámbito hispánico [...]; pero en algunos países como la Argentina o Cuba se usa normalmente en masculino, que es el género que tiene este sustantivo en portugués ( $D P D:$ : s. v. samba).

También se pueden encontrar casos en los que el cambio de género se haya producido a partir de un reanálisis por resegmentación, de modo que se adecua el género a la terminación. Este es el caso de la palabra miasma o de la voz ratio, que se exponen a continuación:

miasma. [...]. Conserva el género masculino que tiene en francés, de donde pasó al español a finales del siglo XVIII: [...]. Hoy se está extendiendo, incluso entre hablantes cultos, su uso en femenino, por influjo de la - $a$ final (DPD: s. v. miasma).

ratio. [...]. Este latinismo es etimológicamente femenino, y así se recomienda usarlo en español [...]; pero por influjo de la -o final se usa hoy frecuentemente en masculino, especialmente en el ámbito de la economía, donde también puede haber influido el género masculino del sustantivo índice (DPD: s. v. ratio).

Finalmente, es posible hallar ejemplos en los que la fuerza analógica ha provocado que se cree una nueva palabra para expresar el género. Tal es el caso del vocablo ogra, como puede observarse: 
ogro -esa. Con el sentido de 'ser imaginario que se alimenta de carne humana', el femenino etimológico y más usado en la lengua culta es ogresa (del fr. ogre, fem. ogresse) [...]. Pero, por analogía con el femenino en - $a$ propio de los sustantivos cuyo masculino acaba en -o, se emplea también el femenino regular ogra (DPD: s. v. ogro -esa).

Además, la diacronía también es de gran importancia en relación a las especializaciones del género en función del significado de la palabra. Es decir, como es bien sabido, determinadas voces que se empleaban en ambos géneros acaban por usarse con un género determinado en función de su significado. Este es el caso del vocablo cometa que es femenino cuando hace referencia al juego infantil, pero masculino cuando designa el astro. Este hecho se refleja también en palabras como canal o dote (además de en crisma o margen):

canal. Aunque en el español antiguo, al igual que en latín, se documenta su uso indistinto en ambos géneros, en el español actual es voz masculina o femenina dependiendo de sus acepciones: a) Es masculina cuando significa 'cauce artificial para la conducción de agua' o 'cauce natural de poca anchura' [...]. b) Se usa mayoritariamente en femenino cuando significa 'res abierta en canal' [...]. c) Se usa en ambos géneros cuando significa 'parte más profunda y limpia de la entrada de un puerto' (DPD: s. v. canal).

dote. Cuando significa 'conjunto de bienes aportados por la mujer al matrimonio o por la religiosa al convento', es válido su uso en ambos géneros, aunque hoy predomina claramente el femenino, que es, además, el género etimológico [...]. Cuando significa 'cualidad personal' es siempre femenino y se emplea normalmente en plural (DPD: s. v. dote).

Por último, el $D P D$ también pone de manifiesto los cambios en la expresión del género de algunas palabras no sólo con respecto a su étimo, sino también en relación a otras etapas anteriores del español, aspecto que se trata pormenorizadamente en el siguiente apartado. Esto se produce, sobre todo, en la designación de nombres sexuados como, por ejemplo, huésped, poeta, sacerdote o sastre. En estas voces se indica que, aunque en épocas anteriores del español tenían o bien un femenino etimológico (como poetisa para poeta o sacerdotisa para sacerdote) o bien generado a partir de un proceso de hipercaracterización ${ }^{1}$ (como huéspeda para huésped o sastra para sastre), en la actualidad todas estas voces también se emplean como comunes en cuanto al género, es decir, la huésped, la poeta, la sacerdote o la sastre:

huésped. [...]. Su femenino tradicional es huéspeda, que aún se documenta en la actualidad [...]; pero hoy parece preferirse su uso como común (el/la huésped) (DPD: s. v. huésped).

poeta -tisa. [...]. El femenino tradicional y más usado es poetisa [...]. Modernamente se utiliza también la forma poeta como común en cuanto al género (el/la poeta) (DPD: s. v. poeta-tisa).

sacerdote -tisa. [...]. El femenino etimológico y tradicional es sacerdotisa, usado especialmente en referencia a religiones antiguas o no cristianas [...]; pero para referirse hoy a las mujeres que ejercen el sacerdocio en las Iglesias cristianas que lo permiten, se prefiere el uso de la forma sacerdote, que funciona en ese caso como común (el/la sacerdote) (DPD: s. v. sacerdote-tisa).

sastre -tra. [...]. Aunque por su terminación sería normal su uso como sustantivo común en cuanto al género (el/la sastre), el único femenino documentado para esta voz es sastra, registrado ya en

1 Denominamos hipercaracterización al proceso de asignación de una clara marca de género (- $a$ para femenino; - $o$ para masculino) al sustantivo o adjetivo (véase Penny 1991/1993). 
el diccionario de Nebrija (1495) [...]. No es normal, y debe evitarse, el femenino ${ }^{{ }_{\text {Sastresa }}}$ (DPD: s. v. sastre-tra).

En definitiva, el criterio etimológico ayuda a clarificar el género que en la actualidad tienen determinados vocablos y a comprender mejor la solución señalada por la norma. Por eso, consideramos que debería extenderse a otros casos que no presentan esta información en los que sería igualmente explicativa.

\subsection{LA HISTORIA DE LA LENGUA COMO NORMA}

En otros casos, el $D P D$ no recurre a la etimología de la palabra para refutar, reafirmar o clarificar su género, sino que se apoya en la historia de la lengua, es decir, señala la existencia de un cambio de género en una determinada voz en contraste con épocas anteriores del español.

Los períodos temporales más empleados en este sentido son el español medieval y el español clásico tomados como referencia por separado ${ }^{2}$ (como en bachiller, cicerón, hipérbole u olor) o conjuntamente (como en cabro, fantasma, hermafrodita o puente). Véanse ejemplos de ambos usos:

olor. [...]. Como se ve en los ejemplos, es un sustantivo de género masculino. Debe evitarse su uso en femenino, frecuente en el español medieval, pero relegado hoy al habla popular y ajeno, por tanto, a la norma culta (DPD: s. v. olor).

bachiller. [...]. En el español clásico se usó el femenino bachillera, casi siempre con intención humorística o despectiva, forma que aún pervive y se usa, en algunas zonas, sin connotaciones negativas (DPD: s. v. bachiller).

fantasma. [...]. Aunque en el español medieval y clásico se usó mayoritariamente en femenino — de lo que aún quedan vestigios en el habla popular y, a veces, literaria—, en el español general actual es de género masculino (DPD: s. v. fantasma).

En todos estos ejemplos, la información histórica que hace referencia a estos períodos concretos del español puede presentar tres usos. En primer lugar, se emplea para justificar la existencia o conservación de una determinada forma (como en el caso de cabro); en segundo lugar, para rebatir o rechazar su uso en la actualidad (como en la voz hermafrodito); y, finalmente, para dar información adicional, sin intención normativa (como en la tigre o la vigía). Véanse los siguientes ejemplos:

cabra. [...]. Para designar específicamente al macho se usan, en la lengua general, las expresiones macho cabrío, cabrón o chivo; no obstante, en algunos países americanos y algunas regiones de España se emplea también el masculino cabro, normal en el español medieval y clásico (DPD: s. v. cabra).

hermafrodita. [...]. El masculino hermafrodito, documentado en el español medieval y clásico, es hoy inusitado y, por ello, desaconsejable, salvo cuando, como nombre propio y escrito, por tanto, con mayúscula inicial, se refiere al hijo de Hermes y Afrodita, origen etimológico de esta voz (DPD: s. v. hermafrodita).

2 Aparte de olor, el único vocablo al que se hace una referencia histórica sólo sobre el español medieval es azúcar. Sin embargo, el comentario trata en este caso sobre la pervivencia del alomorfo femenino del artículo el ante sustantivos también femeninos que empezaban por vocal, construcción propia y exclusiva de este período (cfr. el azúcar molida). 
tigre -esa. [...]. En el español medieval y clásico era normal el uso de la forma tigre como común en cuanto al género (el/la tigre) (DPD: s. v. tigre -esa).

vigía. [...]. Cuando significa 'persona dedicada a vigilar desde una atalaya', es común en cuanto al género (el/la vigía) [...]. En el español medieval y clásico se usó como epiceno femenino y, por tanto, se decía la vigía incluso en referencia a un hombre (DPD: s. v. vigía).

Aparte de los casos anteriores, aunque en menor número, el $D P D$ realiza una serie de indicaciones temporales mucho más concretas en donde toma como punto de referencia el concepto de siglo. De este modo, la indicación histórica puede servir para señalar la incorporación al español de un vocablo con un género determinado, como sucede con la palabra superávit, procedente de una forma verbal latina que carecía de género, la cual se empezó a utilizar como sustantivo masculino en el siglo XVIII en el lenguaje económico. O también se puede usar para marcar un momento a partir del cual un vocablo sufre un cambio de género, como ocurre con lis, sólo femenina hasta el siglo XIX, pero también masculina a partir del siglo XX. O incluso puede ser empleada para especificar un breve período de tiempo durante el cual se produjo la aparición de una nueva forma, sin que ésta llegara a triunfar, como sucedió con confidenta, femenino de confidente:

confidente. [...]. Por su terminación, es común en cuanto al género, y así se usa mayoritariamente en el habla culta (el/la confidente) [...]. Se desaconseja el femenino confidenta, que tuvo cierto uso en el siglo XIX, pero que no se ha consolidado en el nivel culto (DPD: s. v. confidente).

Así como en los ejemplos anteriores (superávit, lis), la información diacrónica era empleada para explicar cuándo se produjo un cambio de género, en este último caso (confidenta) sirve de nuevo para rechazar cualquier empleo actual de una forma determinada de género, que sólo tuvo un «cierto uso» en una época anterior muy concreta.

Finalmente, y de forma totalmente opuesta a todo lo anterior, el $D P D$ puede utilizar conceptos temporales mucho más amplios que los vistos hasta ahora para proporcionar información histórica. En estos casos, la referencia temporal viene dada, en unas ocasiones, por la forma adverbial «tradicionalmente», como sucede con los vocablos tema y polizón, en donde se utiliza en ambos para comentar el inicio de un cambio reciente de género que se está produciendo en estos momentos en la lengua, en contraste con su uso habitual durante toda su existencia. Así, tema 'manía', además del género femenino «tradicional» habría pasado a ser usado también en masculino; y polizón estaría incorporando el femenino polizona, como así lo señala el lema de la entrada (polizón, -na):

tema. [...]. Con el sentido de 'manía o idea fija en la que alguien se obstina', se ha usado tradicionalmente en femenino [...]; pero también se emplea en masculino, por contagio del género propio del resto de las acepciones (DPD: s. v. tema).

polizón -na. [...]. Se ha usado tradicionalmente como epiceno masculino [...]. Pero comienza a usarse con normalidad el femenino polizona, morfológicamente correcto (DPD: s. v. polizón -na).

En otros casos, la expresión que emplea el $D P D$ es la de «ha sido siempre». De este modo, esta referencia temporal se usa, por un lado, para constatar la única posibilidad de género que tiene y ha tenido una determinada palabra (hinchazón y tablazón, como femeninas en su uso culto general), sin que se dé más elección; o sirve, por otro lado, para escoger una deter- 
minada opción de género ante la existencia de dos posibilidades de formación (linde, de uso mayoritario femenino siempre, a pesar de poder ser empleada en ambos géneros; o jefa, como femenino de jefe):

jefe. [...]. Por su terminación, es común en cuanto al género (el/la jefe) [...]; pero cuando el jefe es una mujer ha sido siempre más frecuente el uso del femenino específico jefa, registrado en el diccionario académico desde 1837 (DPD: s. v. jefe).

Como se puede comprobar fácilmente, los criterios históricos vuelven a ser utilizados o como corroboración de la existencia de una determinada realidad morfológica ante la que no es posible otra opción (la hinchazón, la tablazón), o como argumento y prueba a la hora de decidir ante dos posibilidades (la linde frente a el linde; la jefa frente a la jefe).

\subsection{EL USO ACTUAL COMO NORMA}

Tal y como se afirma en su prólogo, el $D P D$ se basa en el uso actual y, por tanto, la mayoría de las referencias temporales que en él aparecen se refieren al «hoy». La lengua actual aparece en muchos casos como un criterio de autoridad que permite rechazar o afirmar un género o preferir el uso de uno respecto a otro.

En primer lugar, curiosamente, la expresión temporal puede dar cuenta no del género de la palabra que aparece en la entrada, sino de la forma de los determinantes que se le anteponen. Se trata de un grupo importante compuesto por aquellos vocablos femeninos que comienzan por /a-/ tónica, como es el caso de acta, agua, águila, alma, alta, ama, área, arma, arpa, asma, aula, habla o hambre, en donde la anteposición directa del artículo conlleva la presencia de la variante morfológica de femenino el. Sin embargo, cuando el artículo es sustituido por un indefinido, se señala la preferencia mayoritaria «hoy» de las formas apocopadas femeninas un, algún, ningún, frente a una, alguna, ninguna, que no son consideradas incorrectas:

agua. [...]. Este sustantivo es femenino. Al comenzar por /a/ tónica, exige el uso de la forma el del artículo definido si entre ambos elementos no se interpone otra palabra, pero los adjetivos deben ir en forma femenina [...]. En cuanto al artículo indefinido, aunque no se considera incorrecto el uso de la forma plena una, hoy es mayoritario y preferible el uso de la forma apocopada un [...]. Lo mismo ocurre con los indefinidos alguno y ninguno: algún agua, ningún agua. El resto de los adjetivos determinativos debe ir en femenino: esta agua, toda el agua, mucha agua, etc. (DPD: s. v. agua).

Por otro lado, cuando la lengua actual es la que impone la solución, el diccionario también se sirve de referencias cuantitativas que lo apoyan en las soluciones propuestas, de modo que se señala que «hoy es mayoritario o preferible» el masculino o el femenino, en función de la voz. Esto sucede con el adjetivo hugonote, el cual «tiende a usarse mayoritariamente» en español actual con una sola terminación y como sustantivo común en cuanto al género (el/la hugonote), aunque ha conservado hasta hoy también como adjetivo dos terminaciones (hugonote, -ta); o con antípoda, en donde el argumento temporal tiene que ver con su mayor frecuencia de uso como femenino, a pesar de su empleo indistinto en ambos géneros; o con autodidacta, 
adjetivo en un principio de dos terminaciones en función del género del sustantivo al que acompaña (autodidacto, $-t a$ ), pero que se está reduciendo a una sola terminación:

autodidacto -ta. [...]. Aún sigue vigente su uso originario como adjetivo de dos terminaciones, una para cada género [...]. Pero hoy es más frecuente usar la forma autodidacta también para el masculino (DPD: s. v. autodidacto -ta).

La gradualidad temporal, esgrimida como argumento anteriormente, se refuerza en el $D P D$ mediante la expresión «hoy predomina», como sucede con la selección del género de los vocablos autoclave, contraluz y tizne, en donde el valor masculino ha triunfado sobre el femenino; o rompiente, en donde el femenino ha sido el elegido por los hablantes, a pesar de que todos éstos se usan en ambos géneros. O también con la frase «hoy se está extendiendo», como ocurre con miembro y rehén, cuyo empleo como sustantivos epicenos masculinos (ella es un miembro del equipo; ella es un rehén de los atracadores) está siendo sustituido por su utilización como comunes en cuanto al género (el/la miembro, el/la rehén). Además, dentro de este gran grupo, se pueden incluir todas aquellas palabras en las que el valor temporal indica claramente una elección normativa, ya que, a diferencia de los ejemplos anteriores, sólo se considera correcta más o menos una única opción. Así tenemos vocablos como alar$m a$, en el que «hoy solo es normal» el valor femenino, a pesar de haber sufrido una vacilación de género en otras épocas; tilde, que con el significado de 'lo más mínimo', «hoy se usa siempre» con género femenino; vertiente, el cual «hoy se emplea casi exclusivamente» como femenino, aunque es válida su utilización en ambos géneros; y aleluya, en el que «hoy suele ser más normal» su valor masculino, a pesar de que también se permite su uso en ambos géneros. Y también podríamos añadir el vocablo diástole, en donde se combinan perfectamente los tres tipos de referencias temporales vistos a lo largo del presente estudio (etimología, historia de la lengua y español actual), con el fin de justificar la elección normativa realizada en la actualidad:

diástole. [...]. Los diccionarios de la Academia lo calificaron de masculino hasta fines del XIX, lo que explica su frecuente uso con ese género en textos de esa época. Pero hoy solo se considera correcto el femenino, que es, por otra parte, el género etimológico (DPD: s. v. diástole).

En otros casos, la lengua actual se emplea como argumento negativo, pues sirve para rechazar opciones de género que no se consideran válidas porque «carecen de uso en la actualidad». Esto ocurre en voces como azuda, cofrada o estratego en las que se señala su escaso empleo en el español actual y se indica que debe usarse preferiblemente el azud, la cofrade y el estratega, respectivamente:

azud. [...]. Aunque se admite su uso en ambos géneros, es mayoritario y preferible el masculino [...]. Existe también, con este significado, la forma azuda, de género femenino y muy escaso uso en la actualidad (DPD: s. v. azud).

cofrade. [...]. Es común en cuanto al género (el/la cofrade) [...]. El femenino cofrada, documentado en el español clásico, carece de uso en la actualidad (DPD: s. v. cofrade).

estratega. [...]. Es común en cuanto al género (el/la estratega) [...]. Hoy es raro y, por ello, desaconsejable el masculino estratego (DPD: s. v. estratega). 
Finalmente, el argumento temporal utilizado de forma negativa también se emplea cuando la pervivencia del género va unida a un significado determinado (como en el caso de atala$y a)$ o cuando se señala claramente el valor normativo de una opción concreta, frente a otra de influencia externa a la lengua española de uso desaconsejable (como en padrina):

atalaya. Cuando significa 'torre vigía' y 'altura desde la que se divisa mucho espacio de tierra o mar', es femenino [...]; así pues, con este sentido no es correcto su uso en masculino. Sí se usa en masculino con el sentido, poco frecuente hoy, de 'hombre que vigila desde una atalaya' (DPD: s. v. atalaya).

madrina. [...]. Es el femenino que corresponde, en el español general culto, al masculino padrino. Es minoritario y desaconsejable el uso de ${ }^{\otimes}$ padrina, que hoy se debe, en muchos casos, al influjo del catalán, lengua en la que es el femenino de padrí ('padrino') (DPD: s. v. madrina).

Finalmente, la referencia temporal al español actual se emplea en muchos casos de manera neutra, es decir, el diccionario simplemente señala el género con el que se usa una determinada palabra hoy. De hecho, esto debería ser lo habitual en un diccionario de uso como el $D P D$. Es el método empleado en los vocablos almíbar, análisis y zóster (además de en emblema, epifonema, epigrama, ibis, yunque):

almíbar. [...]. En la lengua culta actual es solo de género masculino, por lo que debe evitarse su uso en femenino: el almíbar, no ${ }^{\otimes}$ la almíbar (DPD: s. v. almíbar).

análisis. [...]. En el español actual es siempre masculino: el análisis, no ${ }^{\circledR} l a$ análisis (DPD: s. v. análisis).

zóster. [...]. En el español actual se usa exclusivamente en masculino: el herpes zóster, el zóster (DPD: s. v. zóster).

Además, encontramos también un grupo variado de vocablos en los que la información temporal simplemente expresa el hecho, por un lado, de que «es hoy» una opción de género determinada, como se puede ver en las palabras espada 'matador de toros', común en cuanto al género (el/la espada), y trípode, masculina; o, por otro, de que hoy «sigue vivo» en algunos dialectos, como ocurre con la forma adjetiva de dos terminaciones torcazo, $-z a$ :

espada. Con los sentidos de 'matador de toros' y 'persona diestra en el manejo de la espada', es hoy común en cuanto al género (el/la espada) (DPD: s. v. espada).

trípode. 'Soporte con tres pies' y 'banquillo o taburete de tres pies'. Aunque con el segundo sentido indicado se usó en ambos géneros en épocas pasadas, hoy es voz masculina en todas sus acepciones (DPD: s. v. trípode).

torcaz. [...]. Se usa como adjetivo de una sola terminación (paloma torcaz, palomo torcaz) y como sustantivo común en cuanto al género (el/la torcaz) [...]. La forma torcaz es la usada en la lengua general, aunque en determinadas zonas de España y de América sigue vivo el antiguo adjetivo de dos terminaciones torcazo, -za, usado también como sustantivo (DPD: s. v. torcaz).

En este sentido, son un caso especial los sustantivos que se refieren a oficios, ocupaciones o cargos, etc. Los cambios en la sociedad han provocado que ocupaciones que antes eran desarrolladas por hombres en la actualidad también sean desempeñadas por mujeres y viceversa, lo que plantea numerosas dudas e indeterminaciones en el género. Por ello, la descripción 
histórica que hace el $D P D$ en estos casos es muy valiosa, ya que ayuda al usuario a conocer cuál es la forma correcta o a elegir la más apropiada normativamente. Véase el caso de azafato, donde aparece una extensa y clarificadora justificación temporal:

azafato -ta. [...]. Al ser labores tradicionalmente desempeñadas por mujeres, hasta no hace mucho solo existía la forma femenina azafata; dado que hoy también las realizan hombres, se ha creado, y es plenamente válido, el masculino azafato (DPD: s. v. azafato -ta).

Por último, la solución no es única, por lo que el hablante puede utilizar la que prefiera en cada caso. Así ocurre en voces como alguacil, diabla o endocrino, como se puede ver a continuación:

alguacil. [...]. Por su terminación, es común en cuanto al género (el/la alguacil) [...]. Existe también, aunque se usa menos, el femenino específico alguacila, que en épocas pasadas designaba a la mujer del alguacil, pero que hoy designa también a la mujer que ocupa este cargo. Se desaconseja, por desusado, el femenino ${ }^{\otimes}$ alguacilesa (DPD: s. v. alguacil).

diablo, -a. [...]. El femenino es diabla [...]. Con posterioridad a diabla, se creó el femenino diablesa, menos usado pero también válido (DPD: s. v. diablo -a).

endocrino -na. [...]. La forma endocrino se usa también, por acortamiento de endocrinólogo, para designar al médico especialista en endocrinología. Puede funcionar como común en cuanto al género, como es normal en los acortamientos: el/la endocrino; pero la influencia de la forma femenina del adjetivo hace que hoy sea normal llamar endocrina a la médica que ejerce esta especialidad (DPD: s. v. endocrino -na).

En estos casos, el género tradicional y el moderno resultan ser igualmente válidos en el español actual.

\section{CONCLUSIONES}

En la actualidad, el Diccionario panhispánico de dudas se ha convertido en la obra normativa por excelencia donde el usuario puede encontrar las respuestas a sus preguntas en relación a la corrección lingüística. Aunque no se puede poner en duda que el uso es la base de este diccionario, la diacronía, como se ha podido comprobar, también adquiere protagonismo, sobre todo en las informaciones que hacen referencia al género gramatical. Así, uno de los criterios más importantes a la hora de señalar el género de una determinada voz es el etimológico. Esto significa que el género del étimo se utiliza para ratificar o desechar el que tiene la palabra en el español actual. Con todo, pese a que la mayoría de estas referencias diacrónicas son breves, en ocasiones se realiza una completa historia de la evolución experimentada por el género de una palabra e incluso se señala, a veces, la causa que ha podido provocar que la voz haya cambiado el género con respecto a su étimo o a épocas pasadas. Sin embargo, este empleo de lo etimológico como apoyo a lo normativo, a pesar de que pudiera pensarse que resulta superfluo por ser el $D P D$ un diccionario de dudas, en nuestra opinión, es totalmente necesario y debería generalizarse, pues ayuda a clarificar y comprender la decisión normativa tomada en esta obra.

Por otra parte, también se ha observado cómo el DPD se apoya en la historia de la lengua para reafirmar o refutar el género de una palabra del español actual. En este caso, las referencias al español medieval, al español clásico o a ambos períodos se utilizan, principalmente, 
tanto para justificar la existencia o conservación de una determinada forma como para rechazar su uso o expresar simplemente el momento en que se produjo un cambio de género.

En contraposición a lo visto antes, el $D P D$ emplea también la lengua actual como criterio de autoridad para afirmar o rebatir, en un vocablo, un género determinado o mostrar preferencia por el uso de uno en concreto. Para ello, se basa ante todo en la frecuencia de utilización, el predominio o la extensión de una forma gramatical, así como en su escaso empleo si se trata de justificar su no aceptación. Sin embargo, en algunas ocasiones, la referencia al español actual se convierte en un simple dato objetivo para señalar el género asignado actualmente a una palabra, información que cobra una gran importancia en el caso de los sustantivos que se refieren a oficios, ocupaciones o cargos, como se ha podido observar.

En definitiva, la información diacrónica es un elemento lingüístico de gran importancia a la hora de establecer la norma gramatical en relación al género. Ello no significa en absoluto que los datos proporcionados por la historia de la lengua sean la única información válida en estos casos, sino que la norma puede ser explicada y, sobre todo, justificada, con mayor o menor acierto, gracias al hecho de tener en cuenta la diacronía, es decir, el cambio lingüístico. De ahí que, en determinadas ocasiones, sean la etimología, los distintos períodos de la historia de la lengua o el simple uso en español actual, de manera independiente o complementaria, los elementos que ayuden a fijar la norma del género gramatical.

Finalmente, la información histórica nos permite comprobar y contrastar los aciertos y errores, si es que así pueden llamarse, cometidos al haber adoptado una serie de soluciones, sin olvidar que, a pesar de la norma, y ya desde los orígenes de la propia lengua, volverá a ser el hablante, en definitiva, el que tenga la última palabra.

\section{REFERENCIAS BIBLIOGRÁFICAS}

Alvar, Manuel y Bernard PotTIER (1983): Morfología histórica del español, Madrid, Gredos.

Azofra Sierra, Ma Elena (2007): «Criterio normativo y uso general culto en el Diccionario panhispánico de dudas», Revista de lexicografía, XIII, pp. 7-16.

Buenafuentes de la Mata, Cristina y Carlos SÁnchez Lancis (2006): «Diccionario y morfología: la información morfológica en la 22a edición del DRAE», en Mar Campos Souto y José Ignacio Pérez Pascual, eds., El Diccionario de la Real Academia Española: ayer y hoy, A Coruña, Universidade da Coruña (Anexos de la Revista de Lexicografía, 1), pp. 25-37.

Buenafuentes de la Mata, Cristina y Carlos SÁnchez LANCis (2008): «La información ortográfica y morfológica en el diccionario: el DRAE (2001) y el Diccionario panhispánico de dudas», en Dolores Azorín y otros, eds., Actas del II Congreso Internacional de Lexicografía Hispánica (Alicante, 19-23 de septiembre de 2006), Alicante, Taller Digital-Universidad de AlicanteFundación Biblioteca Virtual Miguel de Cervantes, pp. 308-314, ed. en CD-ROM.

Buenafuentes de la MatA, Cristina y Carlos SÁnChez LANCIS (en prensa): «El género gramatical: norma y diacronía en el español en contraste con el catalán», en Actes du XXV Congrès International de Linguistique et de Philologie Romanes (Innsbruck, 3-8 de septiembre de 2007). 
Lloyd, Paul M. (1987/1993): Del latín al español: I. Fonología y morfología históricas de la lengua española, Madrid, Gredos.

MenÉndez PidAl, Ramón (19406): Manual de gramática histórica española, Madrid, Espasa Calpe.

PEnNY, Ralph (1991/1993): Gramática histórica del español, Barcelona, Ariel.

Real ACAdemia Española (200122): Diccionario de la lengua española [DRAE], Madrid, Espasa Calpe.

Real Academia Española (2005): Diccionario panhispánico de dudas [DPD], Madrid, Santillana.

Real Academia Española: Banco de datos (CORDE) [en línea]. Corpus diacrónico del español: $<$ http:// WWw.rae.es> (2008).

Real Academia Española: Banco de datos (CREA) [en línea]. Corpus de referencia del español actual: $<$ http://www.rae.es> (2008).

Rodríguez DíEz, Bonifacio (2005): El género: del latín al español. Los nuevos géneros del Romance, León, Universidad de León.

Urrutia CÁRdenas, Hernán y Manuela Álvarez Álvarez (1988²): Esquema de morfosintaxis histórica del español, Bilbao, Universidad de Deusto.

Velando Casanova, Mónica (2006): «El tratamiento del género gramatical en el Diccionario panhispánico de dudas: entre la tradición y la novedad», Hesperia. Anuario de filología hispánica, IX, pp. 225-242. 